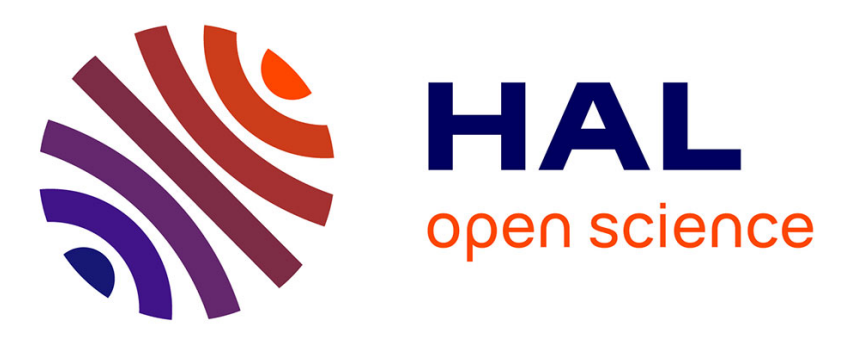

\title{
Influence of monovalent ions on density fluctuations in hydrothermal aqueous solutions by small angle X-ray scattering
}

Cécile da Silva-Cadoux, Jean-Louis Hazemann, Denis Testemale, Olivier Proux, Cyrille Rochas

\section{To cite this version:}

Cécile da Silva-Cadoux, Jean-Louis Hazemann, Denis Testemale, Olivier Proux, Cyrille Rochas. Influence of monovalent ions on density fluctuations in hydrothermal aqueous solutions by small angle X-ray scattering. Journal of Chemical Physics, 2012, 136 (4), pp.044515. 10.1063/1.3679021 . hal00761252

\section{HAL Id: hal-00761252 \\ https://hal.science/hal-00761252}

Submitted on 5 Dec 2012

HAL is a multi-disciplinary open access archive for the deposit and dissemination of scientific research documents, whether they are published or not. The documents may come from teaching and research institutions in France or abroad, or from public or private research centers.
L'archive ouverte pluridisciplinaire HAL, est destinée au dépôt et à la diffusion de documents scientifiques de niveau recherche, publiés ou non, émanant des établissements d'enseignement et de recherche français ou étrangers, des laboratoires publics ou privés. 


\section{AIP ${ }_{\substack{\text { mesoumalor } \\ \text { chemical Physics }}}$}

\section{Influence of monovalent ions on density fluctuations in hydrothermal aqueous solutions by small angle $X$-ray scattering}

Cécile Da Silva - Cadoux, Jean-Louis Hazemann, Denis Testemale, Olivier Proux, and Cyrille Rochas

Citation: J. Chem. Phys. 136, 044515 (2012); doi: 10.1063/1.3679021

View online: http://dx.doi.org/10.1063/1.3679021

View Table of Contents: http://jcp.aip.org/resource/1/JCPSA6/v136/i4

Published by the American Institute of Physics.

\section{Additional information on J. Chem. Phys.}

Journal Homepage: http://jcp.aip.org/

Journal Information: http://jcp.aip.org/about/about_the_journal

Top downloads: http://jcp.aip.org/features/most_downloaded

Information for Authors: http://jcp.aip.org/authors

\section{ADVERTISEMENT}

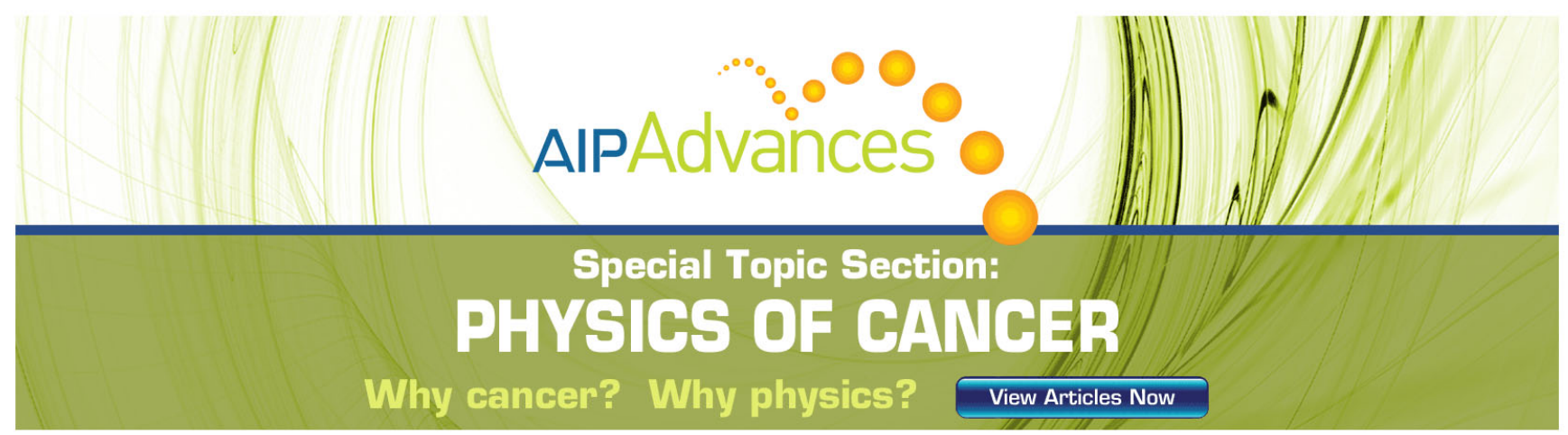




\title{
Influence of monovalent ions on density fluctuations in hydrothermal aqueous solutions by small angle $X$-ray scattering
}

\author{
Cécile Da Silva - Cadoux, ${ }^{1,2, a)}$ Jean-Louis Hazemann, ${ }^{2}$ Denis Testemale, ${ }^{2}$ Olivier Proux, ${ }^{3}$ \\ and Cyrille Rochas ${ }^{4}$ \\ ${ }^{1}$ Department of Civil and Environmental Engineering, Northwestern University, 2145 Sheridan Road, \\ Evanston, Illinois 60208, USA \\ ${ }^{2}$ Département MCMF, Institut Néel, UPR 2940, CNRS, 25 avenue des Martyrs, BP 166, \\ 38042 Grenoble cedex 9, France \\ ${ }^{3}$ Observatoire des Sciences de l'Univers de Grenoble, 414 rue de la piscine, Domaine universitaire, \\ 38400 Saint Martin d'Hères, France \\ ${ }^{4}$ Centre de Recherches sur les Macromolécules Végétales, 601 rue de la Chimie, Domaine Universitaire, \\ 38400 Saint Martin d'Hères, France
}

(Received 8 September 2011; accepted 4 January 2012; published online 26 January 2012)

\begin{abstract}
Synchrotron small angle $\mathrm{X}$-ray scattering measurements on water and alkaline bromine aqueous solutions ( $\mathrm{XBr}$, with $\mathrm{X}=\mathrm{Li}, \mathrm{Rb}$, or $\mathrm{Cs}$ ) were carried out from ambient to supercritical conditions. The temperature was increased from 300 to $750 \mathrm{~K}$ along several isobars between 24 and $35 \mathrm{MPa}$. The correlation length and the structure factor were extracted from the data following the OrnsteinZernike formalism. We obtained experimental evidence of the shift of the critical point and isochore and their dependence on the ions concentration $(0.33 \mathrm{~mol} / \mathrm{kg}$ and $1.0 \mathrm{~mol} / \mathrm{kg})$. We also observed that the size of the density fluctuations and the structure factor increase with the presence of the ions and that this effect is positively correlated with the atomic number of the cation. These behaviors were compared with $\mathrm{ZnBr}_{2}$ and $\mathrm{NaCl}$ systems from the literature. () 2012 American Institute of Physics. [doi:10.1063/1.3679021]
\end{abstract}

\section{INTRODUCTION}

Water plays an important role in a large number of geochemical processes such as hydrothermal or metamorphic reactions. ${ }^{1}$ They include elements transport, in particular metal transport, and physicochemical and thermodynamical reactivity of the phases involved, especially phases in equilibrium (liquid and vapor or liquid and solid). These reactions take place at high temperature $T$ and high pressure $P$, either in liquid, gas, or supercritical phases.

In this supercritical domain, fluids are characterized at the microscopic scale by density fluctuations: areas with gaslike density coexist with area with liquid-like density. ${ }^{2}$ The size of these clusters of molecules diverges when the thermodynamical conditions get closer to the critical point. ${ }^{3} \mathrm{An}$ appropriate tool to characterize such contrast in the distribution of particles is small angle scattering. This technique can be used to determine experimentally the mean size of the density fluctuations (DF) and of the structure factor of the solution.

Small Angle X-ray Scattering (SAXS) or small angle neutron scattering were often used in the literature to study supercritical fluids, such as supercritical carbon dioxide, trifluoromethane or inert gases ${ }^{4-6}$ and supercritical heavy water. ${ }^{7,8}$ Morita et al. worked on supercritical water ${ }^{9,10}\left(P_{C}\right.$ $=22.06 \mathrm{MPa}, T_{C}=647.1 \mathrm{~K}$, and critical density $\rho_{C}$ $=0.322 \mathrm{~g} / \mathrm{ml}$ ) and aqueous solutions (a mixture of water and methanol ${ }^{11}$ ) studied by SAXS. Experimental ${ }^{7,8}$ and

\footnotetext{
a) Author to whom correspondence should be addressed. Electronic mail: c-cadoux@northwestern.edu.
}

theoretical ${ }^{12}$ studies showed that in water the mean size and the structure factor of the DF follow a power law characterized by the critical exponents of water.

In the case of aqueous solutions, ions may change the structure of the fluid and especially the local structure, as studied by Bouazizi et al. ${ }^{13}$ in the case of $\mathrm{NaCl}$ aqueous solutions and by Waluyo et al. ${ }^{14}$ in the case of $\mathrm{NaCl}, \mathrm{MgCl}_{2}$, and $\mathrm{AlCl}_{3}$ aqueous solutions. In our study, we want to characterize the DF and their solvation properties and to observe how these fluctuations are modified by the presence of ions, according to their charge and size. Previously, our group has conducted SAXS measurements on supercritical aqueous solutions of $\mathrm{ZnBr}_{2} \cdot{ }^{15}$ Following this work, we studied this influence of the cations charge and size by exploring the series of monovalent cations (lithium, rubidium, and caesium). The choice of the anion $\left(\mathrm{Br}^{-}\right.$over $\left.\mathrm{Cl}^{-}\right)$was motivated by the possibility to compare the results with X-ray absorption spectroscopy data recently obtained. ${ }^{16-18}$

In aqueous solution, the coordinates of the critical point are not the same as in pure water and depend on the concentration of the solutes. Unfortunately the phase diagram up to the supercritical domain of $\mathrm{XBr}$ solutions is unknown ( $\mathrm{X}$ $=\mathrm{Li}, \mathrm{Rb}$, or $\mathrm{Cs}$ ); we thus based our discussion (Sec. III B) on the phase diagram of sodium chloride aqueous solutions determined by Bischoff and Pitzer. ${ }^{19}$ Indeed, the size of DF and the structure factor at given $T$ and $P$ depend both on the distance to the critical point (which may be displaced by the addition of ions) and on structural changes of the fluid itself; it is difficult to decorrelate these two effects. The intent of this study is to distinguish between the influence that structural 
changes on one hand, and that the critical point shift on the other hand may have on the DF, using comparisons between pure water, $\mathrm{XBr}$ and $\mathrm{ZnBr}_{2}$ solutions.

\section{EXPERIMENT AND ANALYSIS}

\section{A. Experiment}

\section{Small angle $X$-ray scattering}

The coexistence of liquid-like and gas-like areas with different density in the supercritical domain causes a contrast of the electronic (and atomic) density that can be observed by SAXS: X-rays interact with electrons, and their scattering is sensitive to the electronic density. SAXS is thus a relevant method to characterize the DF.

The SAXS measurements have been performed on D2AM-BM02 ("Diffraction et Diffusion Anomale Multilongueurs d'onde"), a French Collaborating Research Group (CRG) beam line at the ESRF ("European Synchrotron Radiation Facility", Grenoble, France).$^{20}$ The beam energy was set to $24 \mathrm{keV}$, corresponding to a wavelength of $0.516 \AA$; and this energy value was enough for the transmission of the beam through the sample and its container to be sufficient for experimental purpose (that is, a total transmission of $12.5 \%$ and $15.2 \%$ for pure water at $30 \mathrm{MPa}$ and, respectively, $303 \mathrm{~K}$ and $713 \mathrm{~K})$. The distance between the sample and the detector was $92 \mathrm{~cm}$ and a charge-coupled device camera was used. With this setup (energy and distance) and the size of the beamstop used $(3 \mathrm{~mm})$, the range for the scattering vector was $0.02-$ $0.63 \AA^{-1}$, in accordance with the $q$-range useful for OrnsteinZernike analysis (Subsection II B).

\section{High pressure-high temperature setup}

An experimental high-pressure vessel was used to control independently the pressure $(P)$ and the temperature $(T)$ in the range of 300-870 K and 0.1-150 MPa. Figure 1 (top part) depicts the geometry of the high-pressure vessel whose description can be found in Ref. 21. The regulation of $P$ was achieved by a new system developed in-house and whose relative precision was $0.01 \mathrm{MPa} ;{ }^{22}$ the accuracy (or absolute precision) of $P$ was $0.5 \mathrm{MPa}$. The temperature was measured with K-type thermocouples: the relative precision was about $0.1 \%$ and the accuracy $\pm 5 \mathrm{~K}$. The thermocouple being separated from the sample by the sample container, the actual temperature of the sample was estimated to be $20 \mathrm{~K}$ less than the measured temperature. This difference of $20 \mathrm{~K}$ was estimated using $\mathrm{X}$-ray absorption measurements on pure water.

Figure 1 (bottom part) depicts also the geometry of the internal cell and its heating system. The internal cell was a tube, made of sapphire, the wall thickness was equal to 125 $\mu \mathrm{m}$ on the beam path and the internal diameter equal to $5 \mathrm{~mm}$. The sample was contained in the cell and can expand thanks to internal pistons. The windows of the vessel were also made of sapphire, with the c-axis oriented along the beam, dome shaped (in order to resist the pressure, while remaining relatively thin) and $0.7 \mathrm{~mm}$ thick.
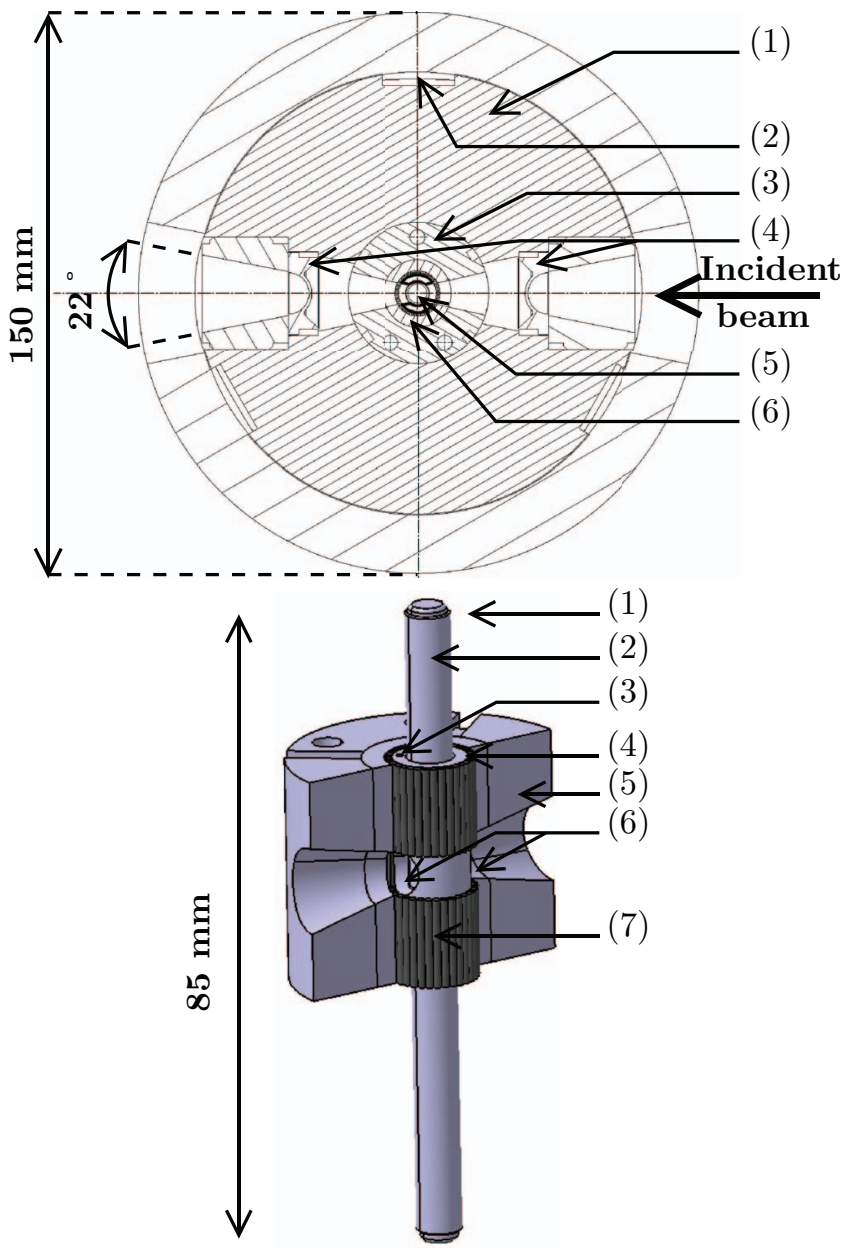

FIG. 1. On the top, drawing of the HP windows geometry with sapphire windows: (1) high pressure vessel main part; (2) water cooling circulation; (3) alumina insulating pieces; (4) sapphire window; (5) sapphire internal cell (internal diameter equal to $5 \mathrm{~mm}$ ); and (6) furnace. On the bottom, 3D drawing of the internal part: (1) internal cell piston; (2) internal cell; (3) thermocouple housing in the copper tube; (4) copper tube; (5) insulating ceramic elements; (6) beam openings in the copper tube; and (7) resistive furnace.

\section{Sample preparation}

The samples studied were water and water with ions: several monovalent cations (lithium, rubidium, and caesium) were associated with bromine, at various concentrations $(0.33$ and $1.0 \mathrm{~mol} / \mathrm{kg}$ ). $\mathrm{XBr}$ aqueous solutions were prepared by dissolving weighted amounts of $\mathrm{LiBr}, \mathrm{RbBr}$, or $\mathrm{CsBr}$ salts (Sigma-Aldrich) in deionized milli-Q water. The different experimental conditions that we investigated are gathered in Table I. Each value of the $P$ corresponds to a density range between 1 and about $0.12 \mathrm{~g} / \mathrm{ml}$ (for pure water). At room temperature, and for these rather low concentrations, all the ions are dissolved. ${ }^{23-25}$

\section{B. Ornstein-Zernike analysis}

Small angle X-ray scattering is used to determine experimentally the size of the DF (correlation length $\xi$ ) and the associated contrast (structure factor $S(0)) .{ }^{3}$ The intensity $I(\mathbf{q})$ 
TABLE I. Experimental conditions of SAXS measurements on supercritical pure water and alkaline bromide aqueous solutions (lithium, rubidium, or caesium). The given concentrations are the salt molalities of the solutions.

\begin{tabular}{lccc}
\hline \hline & $24 \pm 0.5 \mathrm{MPa}$ & $30 \pm 0.5 \mathrm{MPa}$ & $35 \pm 0.5 \mathrm{MPa}$ \\
\hline Pure water & $\ldots$ & $\ldots$ & $\ldots$ \\
Water $+\mathrm{LiBr}$ & $0.33 \mathrm{~mol} / \mathrm{kg}$ & $0.33 \mathrm{~mol} / \mathrm{kg}$ & $0.33 \mathrm{~mol} / \mathrm{kg}$ \\
& & $1.0 \mathrm{~mol} / \mathrm{kg}$ & \\
water $+\mathrm{RbBr}$ & $0.33 \mathrm{~mol} / \mathrm{kg}$ & $0.33 \mathrm{~mol} / \mathrm{kg}$ & $0.33 \mathrm{~mol} / \mathrm{kg}$ \\
Water $+\mathrm{CsBr}$ & $0.33 \mathrm{~mol} / \mathrm{kg}$ & $0.33 \mathrm{~mol} / \mathrm{kg}$ & $0.33 \mathrm{~mol} / \mathrm{kg}$ \\
& & $1.0 \mathrm{~mol} / \mathrm{kg}$ & \\
\hline
\end{tabular}

scattered by a liquid is related to the structure factor $S(\mathbf{q})$ by

$$
\frac{I(\mathbf{q})}{I_{0}(\mathbf{q})}=\frac{1}{n} \int d \mathbf{r} e^{-i \mathbf{q} \cdot \mathbf{r}} \times G(\mathbf{r})=S(\mathbf{q}),
$$

where $\mathbf{q}$ is the scattering vector and $I_{0}(\mathbf{q})$ is the intensity scattered under the assumption that scattering particles are not correlated. This relation follows from the definition of the structure factor as the spatial Fourier transform of the densitydensity correlation function $G(\mathbf{r})$, where $n$ is the atomic density.

For a scattering vector equal to zero, the structure factor can be written as a function either of the isothermal compressibility $\chi_{T}$, or of the fluctuation of the number of particles $N$,

$$
S(0)=n k_{B} T \chi_{T}=\frac{\left\langle(N-\langle N\rangle)^{2}\right\rangle}{\langle N\rangle},
$$

where $T$ is the temperature (in $\mathrm{K}$ ) and $k_{B}$ is the Boltzmann constant. The compressibility $\chi_{T}$ and the structure factor $S(0)$ thus characterize the DF.

The Ornstein-Zernike (O-Z) formalism relates the scattered intensity with the correlation length $\xi$ and the structure factor $S(0)$. Details about this formalism can be found in Ref. 3. It comes down to writing the structure factor as a Lorentzian, as

$$
S(q)=\frac{S(0)}{1+\xi^{2} q^{2}},
$$

where $\xi$ is the correlation length in $\AA$. This length is considered an average size of the DF. Assuming that $I_{0}(q)=I_{0}(0)$ in this $q$-range, Eq. (1) becomes

$$
I(q)=I_{0}(0) \times S(q)=\frac{I_{0}(0) \times \rho k_{B} T \chi_{T}}{1+\xi^{2} q^{2}} .
$$

A linear regression of the inverse of $I(q)$ as a function of $q^{2}$ returns the parameters $\xi$ and $I_{0}(0) \times S(0)$. According to Refs. 26 and 27, the appropriate $q$ fitting range for this linear regression is related to the desired accuracy, that is for $1 \%$ of accuracy, $q \xi$ has to be lower than 3 (in our case, the maximum value of $q \xi$ is around 2.9 , with $\xi_{\max }=23.5 \AA$ and $q_{\max }$ of fitting range equal to $0.122 \AA^{-1}$ ).

\section{Data processing and normalization}

This method is similar to the one previously used in our group. ${ }^{15,28}$ The first step of data processing consisted in extracting the scattered intensity $I(q)$ from the images recorded
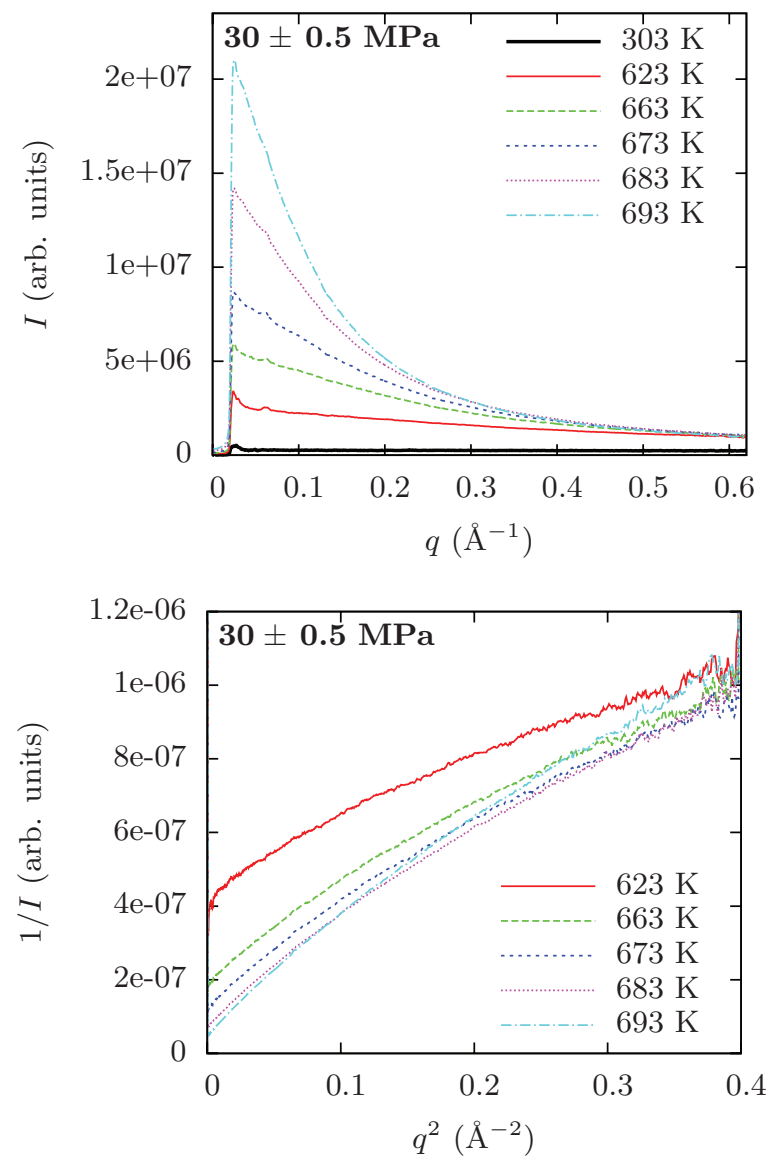

FIG. 2. Experimental intensities $I(q)$ as a function of $q$ (at the top), and corresponding inverse intensities $I(q)$ as a function of $q^{2}$ in the O-Z range (at the bottom), at several temperatures in $\mathrm{K}$ for pure water at $30 \pm 0.5 \mathrm{MPa}$.

by the camera. The camera background was afterward subtracted and the signal was normalized to correct for the variation of the intensity of the synchrotron current and the sample transmission. The images were then radially integrated.

The second step was to subtract the background signal due to the vessel, i.e., the internal cell and the high pressure windows, and to the gas (helium and air) on the beam path. For this purpose, we recorded images with the vessel full of helium at the working pressures, considering that the absorption due to the helium in place of the sample could be neglected. An example of the corrected intensities is given in Figure 2 for pure water at $30 \pm 0.5 \mathrm{MPa}$, between 300 and $700 \mathrm{~K}$. Taking these different steps into account, we estimated the error on $\xi$ and $I_{0}(0) \times S(0)$ to $5 \%$ of their values. More precisely these $5 \%$ include the errors in the normalization process and a parasitic signal coming from the diffraction peaks from sapphire windows and/or inner cell: these peaks may affect the transmitted signal (measured by the scattering of a kapton foil) and, as this parameter is involved in the first step of data processing, may also affect the normalization of the signal.

No particular processing is needed for $\xi$ (Sec. II B). On the contrary, $I_{0}(0) \times S(0)$ must be normalized, as $I_{0}(0)$ depends on the experimental setup. The value of $S(0)$ at low temperature is known ${ }^{29}$ and it could thus be used to normalize $I_{0}(0)$; however, the poor quality of the data at low $T$ makes this approach difficult. On the contrary, the value of $I_{0}(0)$ can 


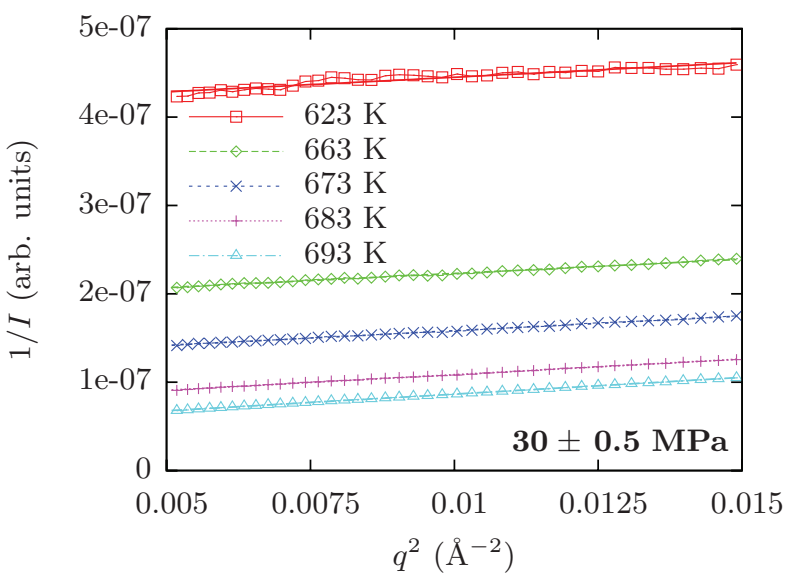

FIG. 3. Comparison between experimental data at several temperatures in $\mathrm{K}$ and the corresponding linear regression for pure water at $30 \pm 0.5 \mathrm{MPa}$.

be more easily measured in the gas phase, but the corresponding value of $S(0)$ is unfortunately unknown. The chosen approach was to determine $I_{0}(0)$ by studying pure water at high temperature (see Sec. III A).

\section{RESULTS AND DISCUSSION}

The size of the DF $\xi$ and the structure factor $S(0)$ were extracted using $\mathrm{O}-\mathrm{Z}$ formalism and the corresponding linear regression. Figure 3 is an example of such a linear regression, showing a very good quality: their Pearson's correlation coefficient is between 0.94 and 0.9999 on the [0.005$0.015 \AA^{-2}$ ] fitted range. Figure 2 shows that the scattered intensity is lower at ambient temperature and the statistic is not as good as at high $T$. In fact, we observed that water exhibits no DF for $T<470 \mathrm{~K}$, and that the scattered signal is then very weak.

\section{A. The case of pure water: Experimental setup validation}

A set of experiments was carried out on pure water at 24, 30 , and $35 \mathrm{MPa}( \pm 0.5 \mathrm{MPa})$ to compare the observed evolution of the DF with theoretical one, in order to validate our setup and methodology. Furthermore, these measurements are used in Sec. III B as a reference to interpret XBr SAXS measurements. Figure 4 shows the variations of the size of the DF and of the (not yet normalized) structure factor. As expected, they are small in the liquid phase, increase in the supercritical domain (but still for high values of $\rho$ ) and decrease again when $\rho$ becomes low. The values and the temperatures at the maximum of these parameters depend on the working pressure. The data collected for pure water, and especially the values of $\xi$, were used to calibrate the experimental setup, which is different from the one previously used in Ref. 15.

\section{The critical isochore and the maximum of the DF}

The critical isochore is defined by the analytic continuation of the coexistence curve between liquid and gas. More precisely, this curve corresponds to states whose density is equal to the critical one $(0.322 \mathrm{~g} / \mathrm{ml})$. The sample density
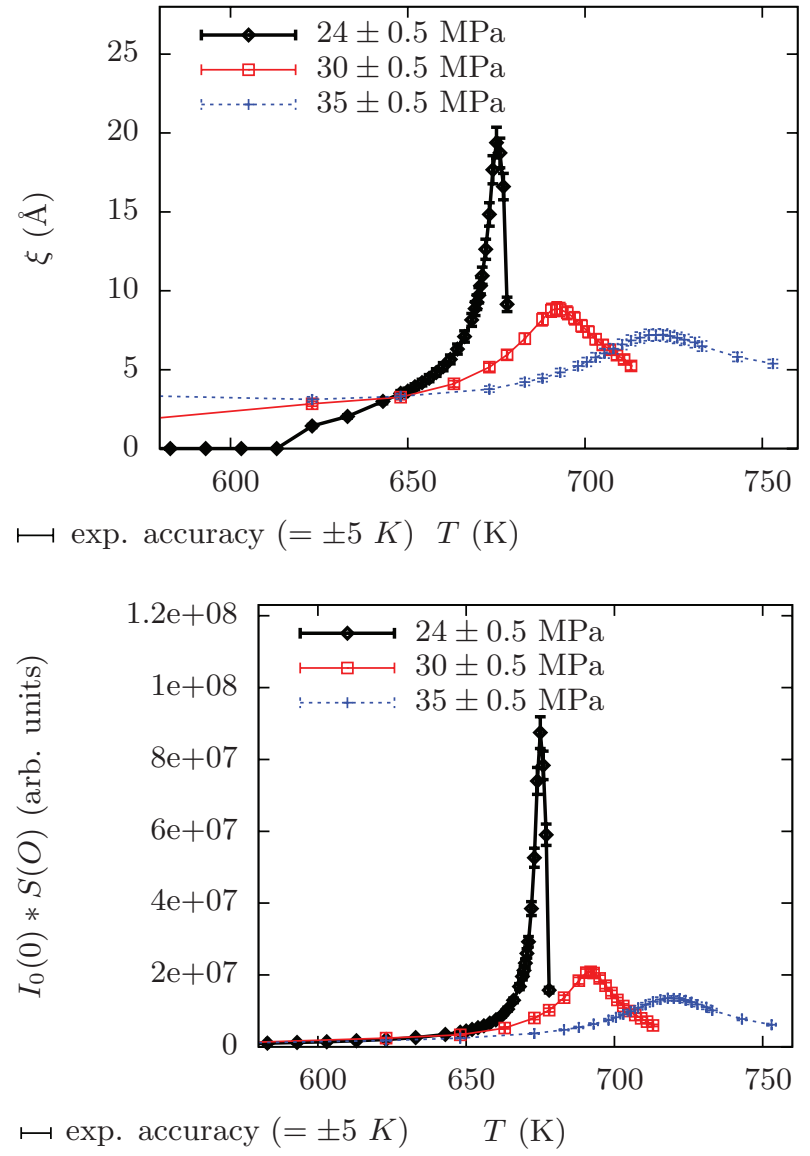

FIG. 4. Evolution of the size $\xi$ in $\AA$ of the DF (at the top) and the structure factor (at the bottom) as a function of $T$ for pure water at 24,30 , and $35 \mathrm{MPa}$ $( \pm 0.5 \mathrm{MPa})$.

can be estimated using transmission measurements: indeed the sample absorbance $A$ is calculated as the logarithm of the ratio between the incident and the transmitted intensity; the Beer-Lambert law relates this parameter to the density $\rho$ of the sample:

$$
\begin{array}{r}
I_{\text {transmitted }}=I_{\text {incident }} \mathrm{e}^{-\frac{\mu}{\rho} \rho x} \\
\Longleftrightarrow \quad A=\ln \left(\frac{I_{\text {incident }}}{I_{\text {transmitted }}}\right)=\frac{\mu}{\rho} \rho x,
\end{array}
$$

where $\mu / \rho$ is the energy-dependent mass attenuation coefficient of the sample (which is tabulated), and $x$ his thickness (fixed in our case). Figure 8 shows the evolution of this absorbance with temperature, where the inflection point of $\rho$ corresponds to the crossing of the critical isochore.

Currently it is not established in the literature that the maximum of the fluctuations corresponds to the critical isochore. Experimental works by Morita et al. ${ }^{9}$ show a difference of density between these two thermodynamical states of $0.04 \mathrm{~g} / \mathrm{ml}$. In our case, for example at $30 \mathrm{MPa}, 0.04 \mathrm{~g} / \mathrm{ml}$ corresponds to $6.6 \mathrm{~K}$, which is in the same order of magnitude as the experimental accuracy $( \pm 5 \mathrm{~K})$. Besides, at $30 \pm 0.5 \mathrm{MPa}$, the experimental maxima of $\xi$ and $S(0)$ occur around $692 \mathrm{~K}$ for the measured temperature, corresponding to $672 \pm 5 \mathrm{~K}$ for the sample temperature (cf. existence of the experimental 
gradient, Sec. II A). This is coherent with the theoretical temperature at the crossing of the critical isochore, equal to $675.8 \mathrm{~K}^{30}$ We will thus assume that the crossing of the critical isochore coincides with the maximum of the DF, following the same method as in Ref. 15.

In the neighborhood of the critical isochore, the density fluctuations become more and more intense. From a thermodynamic point of view their size and the structure factor diverge at the critical point. More precisely, the thermodynamic equation of state can be expressed by reduced variables and the divergent values follow power laws, defined by critical exponents, linked to the universal class of the fluid; these exponents can be calculated based on a three-dimensional (3D) Ising-type model for the fluid. According to Refs. 7, 8, and 15 , along the critical isochore, the maximum values of $\xi$ and $S(0)$ can thus be expressed by

$$
\xi=\xi_{0} t^{-v} \quad \text { and } \quad S(0)=n_{C} k_{B} T_{C} p_{C}^{-1} \Gamma \frac{T}{T_{C}} t^{-\gamma},
$$

where $v$ and $\gamma$ are the critical exponents, $n_{C}$ is the atomic density at the critical point, $t$ defined as $t=\left(T-T_{C}\right) / T_{C}$, $P_{C}$ is the critical pressure, $\xi_{0}$ and $\Gamma$ are the amplitudes of the parameters ( $\xi$ and $S(0)$ ) and $T$ is expressed in Kelvin. In the case of heavy water $\mathrm{D}_{2} \mathrm{O},{ }^{12}$ these parameters have been evaluated as

$$
\begin{gathered}
\xi_{0}=1.28 \AA, \\
n_{C} k_{B} T_{C} p_{C}^{-1} \Gamma=0.802, \\
v=0.630, \\
\gamma=1.242 .
\end{gathered}
$$

Wyczalkowska et al. ${ }^{31}$ and Veloso ${ }^{32}$ show that these parameters $\left(\xi_{0}, \Gamma, v\right.$, and $\left.\gamma\right)$ are the same for water as for heavy water; as the coordinates of the critical point change between water and heavy water, it comes down that $n_{C} k_{B} T_{C} p_{C}^{-1} \Gamma$ $=0.716$ in the case of water.

Figure 5 shows the maxima of $\xi$ and $S(0)$ as a function of $P$. The value of $I_{0}(0)$ at $35 \pm 0.5 \mathrm{MPa}$ was computed based on the theoretical value of $S(0)$ at this pressure, predicted by the thermodynamical Ising model. The corresponding $I_{0}(0)$ was considered constant for other values of $P$. The reason for fitting $I_{0}(0)$ based on the experimental result obtained at $35 \pm 0.5 \mathrm{MPa}$ only and not using a regression based on the three experimental points is that the data obtained at high pressure is assumed to be more precise. Figure 5 shows that the values of $S(0)$ at 24 and $30 \mathrm{MPa}( \pm 0.5 \mathrm{MPa})$ are also fitted reasonably well. The differences between the experimental and theoretical values of $\xi$ and $S(0)$ are satisfactory, thus validating the whole setup. Besides assuming constant $I_{0}(0)$ over the experimental $T$ range, $S(0)$ was normalized for each $\mathrm{XBr}$ solutions using the theoretical value for pure water and this normalized $S(0)$ was used in subsequent data processing.

Section III B studies the evolution of the DF with $T$ and $P$ along several isobars. In particular, the maximum amplitude
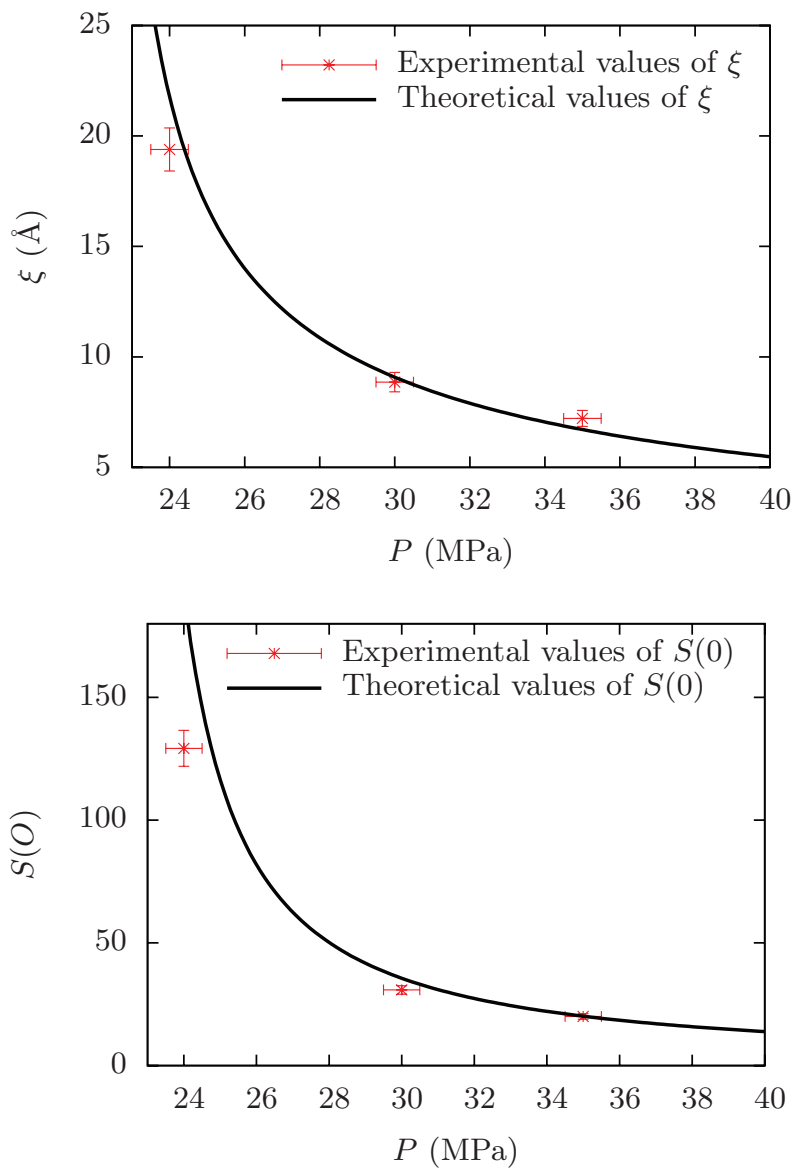

FIG. 5. Maximum of $\xi$ in $\AA$ (top) and $S(0)$ (bottom) as a function of $P$ for pure water: comparison between the experimental and theoretical values. The experimental value of $S(0)$ at $35 \pm 0.5 \mathrm{MPa}$ was adjusted to the theoretical one.

of the size $\xi$ of the DF and of the structure factor $S(0)$ along each isobar are observed for the various samples.

\section{B. Influence of ions on the density fluctuations}

\section{Effect of the cation at 30 and $35 \mathrm{MPa}$}

Figures 6 and 7 show the variations of the size of DF and of the structure factor as a function of $T$ for pure water and aqueous solutions at 30 and $35 \mathrm{MPa}( \pm 0.5 \mathrm{MPa})$, at several concentrations. The data for the $\mathrm{RbBr}$ aqueous solution at $35 \pm 0.5 \mathrm{MPa}$ is not complete because of an experimental problem during the acquisition. Several effects emerge from the qualitative analysis of the data at $0.33 \mathrm{~mol} / \mathrm{kg}$ :

- The temperature at the maximum of $\xi$ and $S(0)$ is the same for water and for the various ions dissolved in the solution, within the experimental accuracy of $T$.

- The maximum value of $\xi$ depends on the cation in solution. At 30 and $35 \mathrm{MPa}( \pm 0.5 \mathrm{MPa})$ these values seem to be correlated with the ionic radius of the cation, that is, $\xi_{\max }$ (water) $\ll \xi_{\max }(\mathrm{LiBr})$ $\ll \xi_{\max }(\mathrm{RbBr}) \leq \xi_{\max }(\mathrm{CsBr})$, their ionic radius being $0.74 \AA$ for $\mathrm{Li}, 1.5 \AA$ for $\mathrm{Rb}$, and $1.7 \AA$ for $\mathrm{Cs} .{ }^{33} \mathrm{The}$ maximum values of $S(0)$ follow the same trend. 


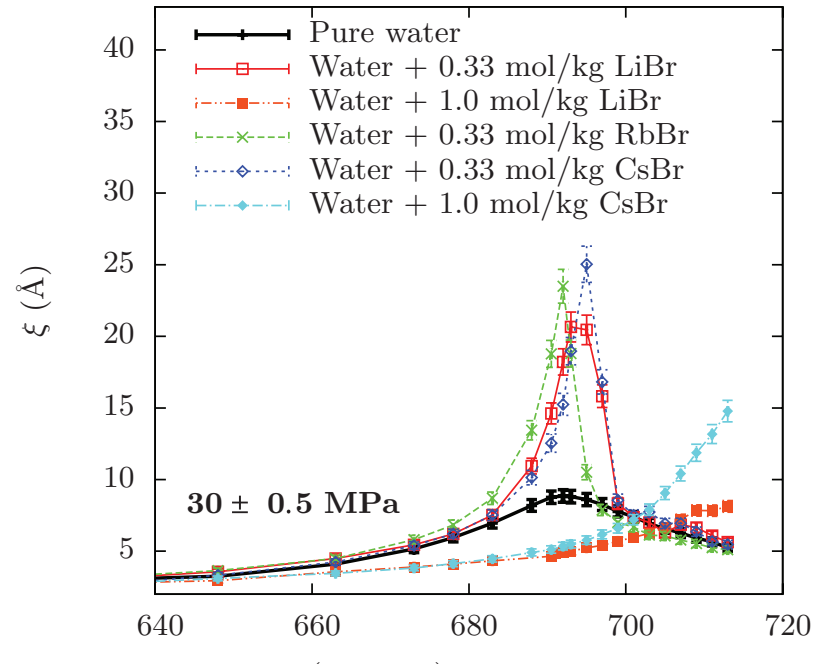

$\longmapsto$ exp. accuracy $(= \pm 5 K) T(\mathrm{~K})$

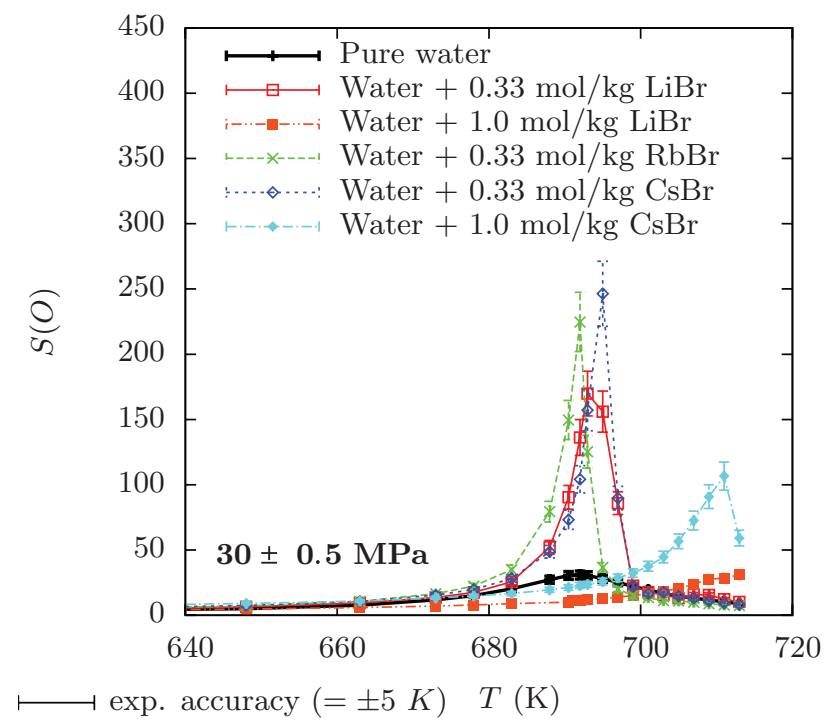

FIG. 6. Evolution of the size $\xi(\AA)$ of DF (top) and of the structure factor $S(0)$ (bottom) as a function of $T$ at $30 \pm 0.5 \mathrm{MPa}$ for pure water and $\mathrm{XBr}$ aqueous solutions $(0.33$ and $1.0 \mathrm{~mol} / \mathrm{kg})$.

As the temperature increases, the density fluctuations attain a maximum, corresponding to the crossing of the critical isochore at the working pressure (Sec. III A). Figures 6 and 7 show that this temperature is not shifted by the addition of the ions at this concentration, compared with the case of pure water (within the experimental accuracy of $T$ ).

\section{Effect of the concentration at constant pressure}

Figure 6 also shows the evolution of the size of DF and of the structure factor as a function of $T$, for aqueous solutions of $\mathrm{LiBr}$ and $\mathrm{CsBr}$, with ions concentration of $0.33 \mathrm{~mol} / \mathrm{kg}$ and $1.0 \mathrm{~mol} / \mathrm{kg}$, at $30 \pm 0.5 \mathrm{MPa}$. Indeed, the concentration was changed only for lithium and caesium because their size is the most different among the initial list of cations $(\mathrm{Li}, \mathrm{Rb}$, and $\mathrm{Cs}$ ).

The density of the system is proportional to the sample absorbance (cf. Eq. (5) above). Figure 8 shows that, at 30

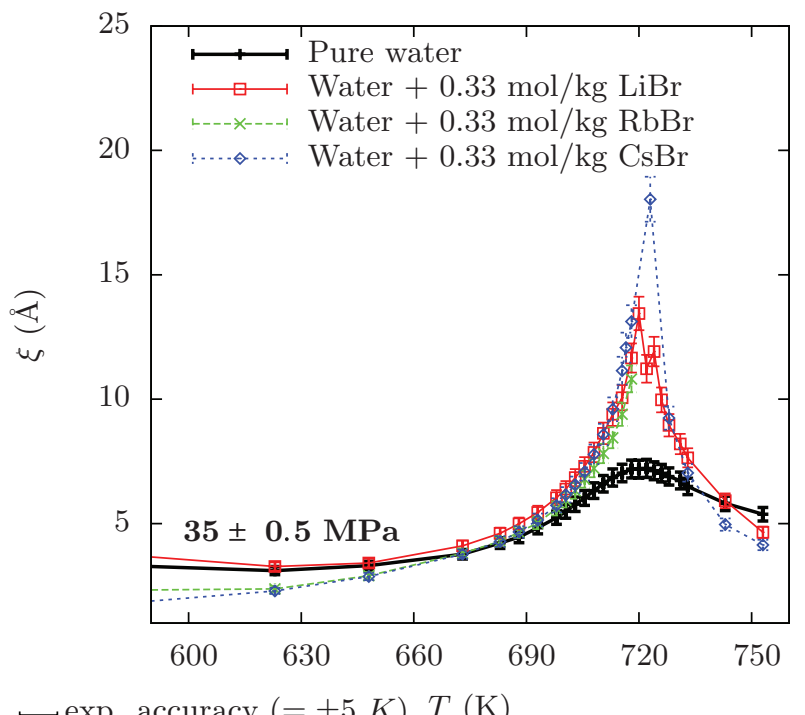

$\longmapsto$ exp. accuracy $(= \pm 5 K) T(\mathrm{~K})$

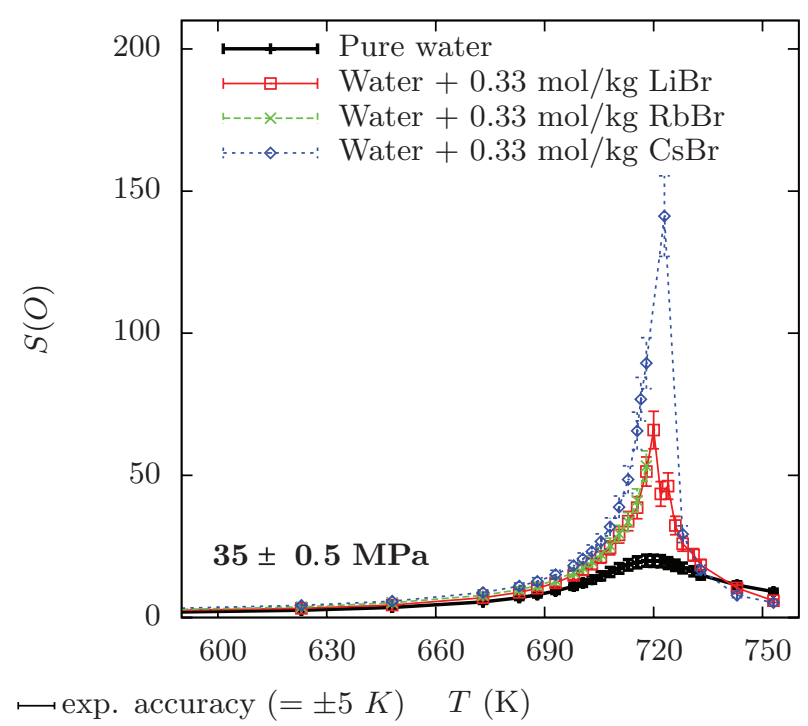

FIG. 7. Evolution of the size $\xi(\AA)$ of DF (top) and of the structure factor $S(0)$ (bottom) as a function of $T$ at $35 \pm 0.5 \mathrm{MPa}$ for pure water and $\mathrm{XBr}$ aqueous solutions $(0.33 \mathrm{~mol} / \mathrm{kg})$.

$\pm 0.5 \mathrm{MPa}$, the sample absorbance curve of aqueous solutions is similar in shape to that of pure water; additional experimental data not reported here showed the same effect at 35 $\pm 0.5 \mathrm{MPa}$. It is also similar to classical X-ray absorption measurements (see, for example, Ref. 34). Figure 8 also shows that the inflection point of these ratios, corresponding to the crossing of the critical isochore, seems to be at much higher temperature for concentrated solutions. For diluted solutions, the inflection point is conversely lower than for pure water, but the difference is around $5 \mathrm{~K}$, which is in the same order of magnitude as our experimental accuracy. Said otherwise, the displacement of the critical isochore to higher $T$ increases with the solute concentration, even if we do not know if this displacement is smooth or involves several stages.

Likewise, the temperature at the maximum of the DF (size and structure factor) is higher for the solutions at $1.0 \mathrm{~mol} / \mathrm{kg}$ than for solutions at $0.33 \mathrm{~mol} / \mathrm{kg}$ (more than 


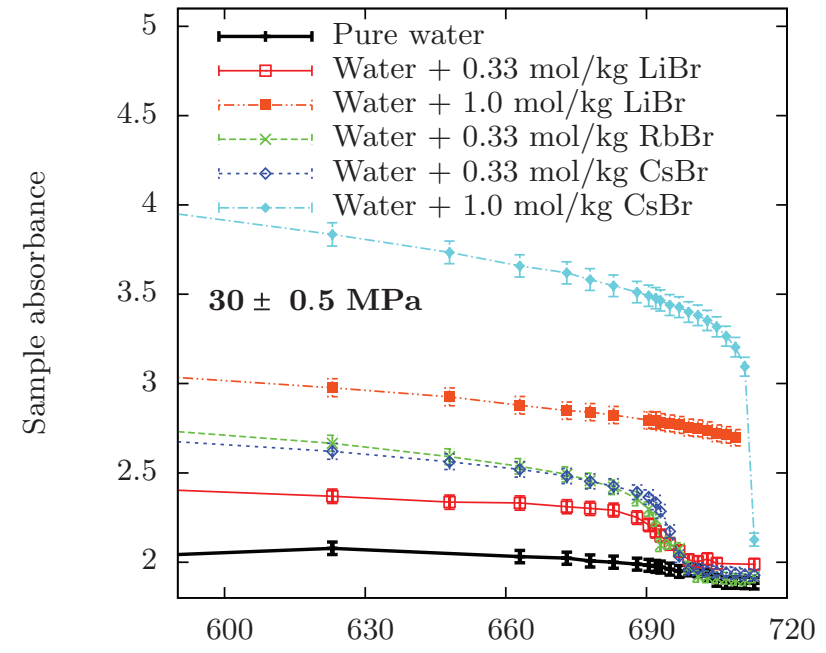

$\longmapsto \exp$. accuracy $(= \pm 5 K) \quad T(\mathrm{~K})$

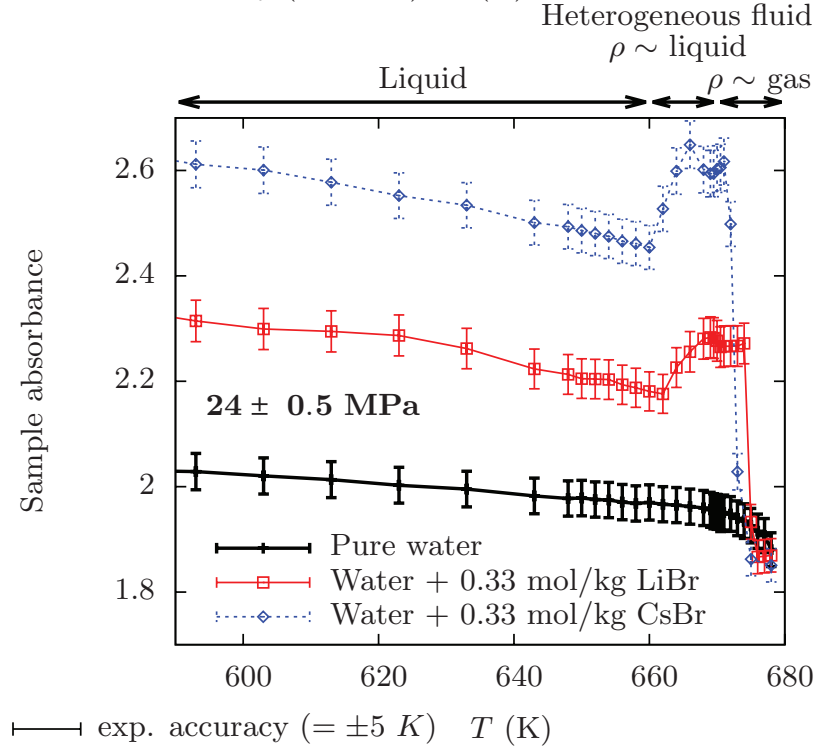

FIG. 8. Evolution of the absorbance of the sample as a function of $T$ at 30 $\pm 0.5 \mathrm{MPa}$ (top) and $24 \pm 0.5 \mathrm{MPa}$ (bottom) for pure water and $\mathrm{XBr}$ aqueous solutions $(0.33 \mathrm{~mol} / \mathrm{kg}$ and $1.0 \mathrm{~mol} / \mathrm{kg})$.

$20 \mathrm{~K})$. Unfortunately, because of experimental constraint, we were not able to reach a high enough temperature to observe the maximum of the DF for the most concentrated solution. Figures 6 and 8 show that the temperature shift of the critical isochore between solutions at 0.33 and $1.0 \mathrm{~mol} / \mathrm{kg}$ is at least $20 \mathrm{~K}$.

\section{Effect of the cation at $24 \mathrm{MPa}$}

Figure 8 shows the sample absorbance as a function of $T$ at $24 \pm 0.5 \mathrm{MPa}$. The behavior is more complex for alkaline bromide aqueous solutions than for pure water: the absorbance decreases slowly until $660 \mathrm{~K}$, as it is the case for pure water, but then quickly increases, reaching a value typical of the liquid phase, and finally decreases quickly to gas-like values. This evolution is thus incompatible with an isobaric shifting of $T$ at $P>P_{C}$, because for this type of solutions the density changes continuously from the liquid phase to the gas phase (e.g., see top part of Figure 8).

The most likely explanation for this phenomenon is that a demixing process occurs, in other words that adding ions shifts the critical point $\left(T_{C \text {, salt }}, P_{C \text {, salt }}\right)$ and that the system is in subcritical conditions at $24 \pm 0.5 \mathrm{MPa}\left(P_{C}\right.$, water $<P$ $\left.<P_{C \text {, salt }}\right)$. Under this assumption, the evolution of the absorbance is explained as follows: from $660 \mathrm{~K}$, the sample is divided in two phases, a liquid one and a gas one. As no precipitation is observed, the liquid phase has to be more concentrated in ions. From around $660 \mathrm{~K}$ to around $675 \mathrm{~K}$, the volume of the liquid phase is more important, and is located at the bottom of the cell, and the X-ray beam goes through a liquid sample. When $T$ increases above $675 \mathrm{~K}$, the volume of the gas phase increases and the X-rays probe a gas-like sample which is less concentrated in ions. The appearance of the gas-like phase reveals the crossing of the liquid-gas coexistence curve; note that this occurs at the same temperature as the crossing of the critical isochore of pure water, within our experimental accuracy. The demixing process makes it difficult to compute $\xi$ and $S(0)$ because the ions concentration in the probed phase is unknown.

To summarize, a demixing process is observed at 24 $\pm 0.5 \mathrm{MPa}$ and for a concentration of $0.33 \mathrm{~mol} / \mathrm{kg}$ : $P$ is below the critical pressure of the fluid and our experimental isobar is crossing the liquid-gas coexistence curve. The new $P_{C}$ is thus higher for a solution at $0.33 \mathrm{~mol} / \mathrm{kg}$ than for pure water, as expected, and lies between 24 and $30 \mathrm{MPa}$.

\section{Change of the critical isochore}

The occurrence of the demixing process shows that $P_{C}$ is higher for ions concentration of $0.33 \mathrm{~mol} / \mathrm{kg}$ than in pure water while the temperature at the maximum of the DF at $30 \pm 0.5 \mathrm{MPa}$, that is at the crossing of the isochore, does not change (or if changes exist, they are lower than $5 \mathrm{~K}$ and they are not experimentally resolved). In other words, adding the ions may move the critical point in the phase diagram, but this change is made along the critical isochore of pure water. This shift thus does not affect the temperature at the crossing of the isochore at $30 \pm 0.5 \mathrm{MPa}$ (Figure 9, which represents a part of the phase diagram of pure water, with our experimental isobars.). However, this temperature does change by at least $20 \mathrm{~K}$ when the concentration reaches $1.0 \mathrm{~mol} / \mathrm{kg}$, which is bigger than our experimental accuracy: the critical isochore is here shifted in temperature.

The phase diagram of the $\mathrm{XBr}(\mathrm{X}=\mathrm{Li}, \mathrm{Rb}$, or $\mathrm{Cs})$ aqueous solutions is not known in this $P-T$ range. As a contrary, the phase diagram of $\mathrm{NaCl}$ aqueous solutions is known: based on thermodynamical data, Bischoff and Pitzer ${ }^{19}$ calculated the modified coordinates of the critical point as a function of the concentration of salt. For a mass concentration of around $2.22 \%$, that is, a $\mathrm{NaCl}$ molar concentration of around $0.38 \mathrm{~mol} / \mathrm{kg}$, the critical point is moved compared with pure water from $647.1 \mathrm{~K} / 22.06 \mathrm{MPa}$ to $673.15 \mathrm{~K} / 28.07 \mathrm{MPa}$. For a mass concentration of $6.1 \%$ (that is $1.03 \mathrm{~mol} / \mathrm{kg}$ ), $P_{C}$ is equal to $36.3 \mathrm{MPa}$, and $T_{C} 703.15 \mathrm{~K}$ (see Figure 9 and Table II). 


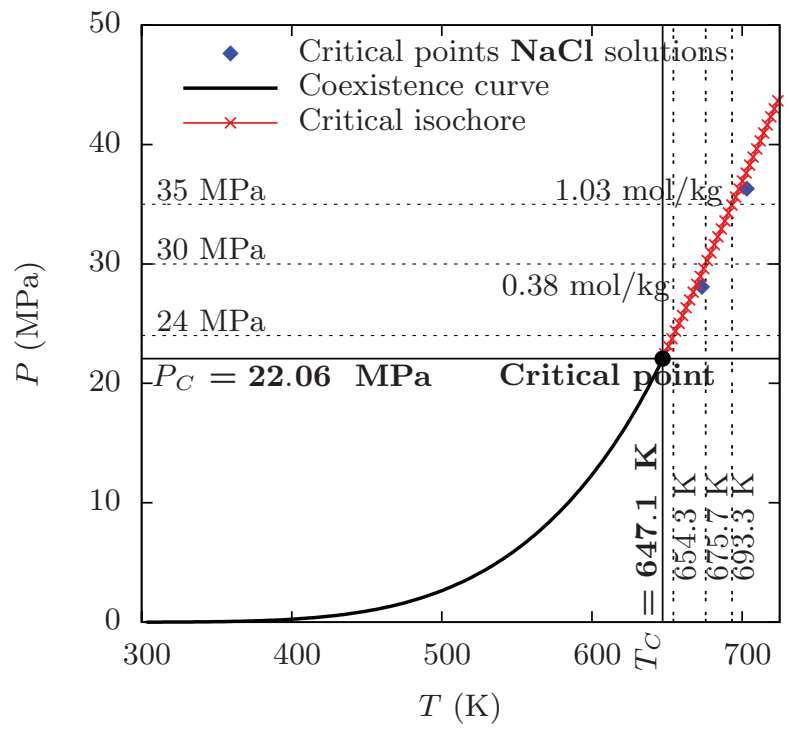

FIG. 9. Liquid-gas coexistence curve and critical isochore for pure water, calculated according to Ref. 30, and critical points of $\mathrm{NaCl}$ aqueous solution $(0.38$ and $1.03 \mathrm{~mol} / \mathrm{kg}) .{ }^{19}$ The solid lines mark the boundaries of the supercritical domain, the horizontal dashed lines the experimental isobars and the vertical ones the corresponding values of the temperature.

The occurrence of the demixing process suggests that the new values of $P_{C}$ is larger than $24 \pm 0.5 \mathrm{MPa}$. This is coherent with the fact that the shift of the critical point for $\mathrm{XBr}$ solutions is expected to be in the same order of magnitude as for $\mathrm{NaCl}$ solution (Figure 9). Besides, at $30 \pm 0.5 \mathrm{MPa}$, the fact that the critical isochore is crossed at the same $T$ as for pure water, is coherent with a shift of the critical point along the critical isochore of pure water, as for $\mathrm{NaCl}$ solutions. Contrary to $\mathrm{NaCl}$ solutions, $\mathrm{XBr}$ solutions at $1.0 \mathrm{~mol} / \mathrm{kg}$ and 30 $\pm 0.5 \mathrm{MPa}$ exhibit a significant temperature shift at the crossing of the critical isochore. Another difference is that a demixing process occurs at $30 \mathrm{MPa}$ for $\mathrm{NaCl}$ solutions (30 MPa being below $P_{C}$ at $1.0 \mathrm{~mol} / \mathrm{kg}$ ), whereas we did not observe it for $\mathrm{XBr}$ solutions.

$\mathrm{ZnBr}_{2}$ aqueous solutions are also good candidates to study the influence of the cation size on DF; in this case, however, the cation charge is different which may also affect the DF. Previous work by Testemale et al. ${ }^{15}$ showed that the temperature shift at the crossing of the critical isochore is around

TABLE II. Observed coordinates change of the critical pressure and of the temperature at the crossing of the critical isochore, with $\mathrm{X}=\mathrm{Li}, \mathrm{Rb}$, or $\mathrm{Cs}$, and comparison with other ions: $\mathrm{NaCl}^{19}$ and $\mathrm{ZnBr}_{2} .{ }^{15}$

\begin{tabular}{lccc}
\hline \hline & $\Delta p_{C}(\mathrm{MPa})$ & $\Delta T_{\text {crossing }}$ \\
\hline $\mathrm{NaCl}$ & $0.38 \mathrm{~mol} / \mathrm{kg}$ & 6.016 & 4 at $28 \mathrm{MPa}$ \\
& $1.03 \mathrm{~mol} / \mathrm{kg}$ & 14.24 & 5 at $36.3 \mathrm{MPa}$ \\
$\mathrm{XBr}$ & $0.33 \mathrm{~mol} / \mathrm{kg}$ & $2<\Delta p_{C}<8$ & $<6$ at 30 and $35 \mathrm{MPa}$ \\
& & & $( \pm 0.5 \mathrm{MPa})$ \\
& $1.0 \mathrm{~mol} / \mathrm{kg}$ & unknown & $>25$ at $30 \pm 0.5 \mathrm{MPa}$ \\
$\mathrm{ZnBr}_{2}$ & $0.3 \mathrm{~mol} / \mathrm{kg}$ & unknown & $\sim 17 \mathrm{~K}$ at $28.5 \mathrm{MPa}$ \\
& & & $\sim 15 \mathrm{~K}$ at $45 \mathrm{MPa}$ \\
& & & $\sim 20 \mathrm{~K}$ at $60 \mathrm{MPa}$ \\
& $1.0 \mathrm{~mol} / \mathrm{kg}$ & unknown & $\sim 16 \mathrm{~K}$ at $60 \mathrm{MPa}$ \\
\hline \hline
\end{tabular}

$15-20 \mathrm{~K}$ at $0.3 \mathrm{~mol} / \mathrm{kg}$ and around $16 \mathrm{~K}$ at $1.0 \mathrm{~mol} / \mathrm{kg}$. Note that in the former case, $\mathrm{ZnBr}_{2}$ solutions exhibit a large temperature shift at the crossing of the critical isochore contrary to $\mathrm{XBr}$ and $\mathrm{NaCl}$ solutions; whereas in the latter case, this large temperature shift is observed both for the $\mathrm{ZnBr}_{2}$ and $\mathrm{XBr}$.

These different behaviors could result from the charge of the cation: a higher charge will increase Coulomb's interaction between the water molecules and the cation. It may thus change the structure of the fluid, and as a consequence its critical coordinates and isochore. In other words, if the ionic charge increases, the influence of the ions on the fluid structure may increase as well and the isochore may be more shifted. Finally, $\mathrm{XBr}$ and $\mathrm{ZnBr}_{2}$ exhibit the same behavior at $1.0 \mathrm{~mol} / \mathrm{kg}$; this suggests that the effect of the charge is smoother for higher concentration.

The displacement of the critical point and isochore with the addition of ions causes the amplitude of $\xi$ and $S(0)$ at a given $T$ and $P$ to change. Indeed, starting from a point on the critical isochore, decreasing $P$ and $T$ to closer to the critical point causes an increase of the maximum values of $\xi$ and $S(0)$. The addition of ions shifts the critical point to higher $T$ and $P$; therefore, increasing the amplitudes of $\xi$ and $S(0)$.

Based on comparison with $\mathrm{NaCl}$ solutions, the increases of both $\xi$ and $S(0)$ with the addition of the ions can be compared with the increases from a shift of the critical point. But it is worth questioning whether this shift of the critical point is sufficient to explain all the changes of $\xi$ and $S(0)$. Assuming that the shift of the critical point is the same for $\mathrm{XBr}$ as for $\mathrm{NaCl}$ solutions, ${ }^{19}$ the distance to the critical point at the crossing of the critical isochore can be evaluated from the experimental results as follows:

- For pure water at $24 \mathrm{MPa}$, the isochore is crossed at $1.94 \mathrm{MPa}$ and $7.2 \mathrm{~K}$ from the critical point, while at $30 \mathrm{MPa}$ it is crossed at $7.94 \mathrm{MPa}$ and $28.6 \mathrm{~K}$ from the critical point. The difference in $T$ at the crossing of the isochore is $21.4 \mathrm{~K}$ for a difference of $P$ of $6 \mathrm{MPa}$.

- For XBr solutions $(c=0.33 \mathrm{~mol} / \mathrm{kg})$, the isochore is crossed at about 1.9 MPa and $2.5 \mathrm{~K}$ from the critical point of $\mathrm{NaCl}$ solutions. The difference between this situation and pure water at $30 \mathrm{MPa}$ is of $6 \mathrm{MPa}$ and $26 \mathrm{~K}$, that is the same difference for $T$ and $P$ as between pure water at 24 and $30 \mathrm{MPa}$.

Assuming that, at $30 \pm 0.5 \mathrm{MPa}$, the addition of ions only affects the DF through the displacement of the critical point, the difference of $\xi$ and $S(0)$ between the $\mathrm{XBr}$ solution at $0.33 \mathrm{~mol} / \mathrm{kg}$ and pure water should be the same as between water at $30 \mathrm{MPa}$ and water at $24 \mathrm{MPa}( \pm 0.5 \mathrm{MPa})$. Indeed, the size $\xi$ of the fluctuations for ions at $30 \pm 0.5 \mathrm{MPa}$ are in the same order of magnitude as for pure water at 24 $\pm 0.5 \mathrm{MPa}(23 \pm 3 \AA$ for the ions at $30 \pm 0.5 \mathrm{MPa}$ and 19.4 $\pm 1 \AA$ for pure water at $24 \pm 0.5 \mathrm{MPa}$, cf. top parts of Figures 4 and 6): to a large extent, the changes of $\xi$ can be explained by the shift of the critical point. On the contrary, the structure factors are very different: $205 \pm 55$ for the ions and $145 \pm 7$ for pure water (bottom parts of Figures 4 and 5).

As a first approximation, the values of the correlation length $\xi$, that is, the size of the DF, reflect their structure and the structure factor $S(0)$ reflects the electronic contrast 
of the density. Under this assumption, the maximum values of $S(0)$ should indeed change with the addition of the ions, whereas the close values of $\xi$ suggest that the structure of the DF is similar for equivalent distance to the critical point. The shift of the critical point could not explain the changes of the DF single-handedly. Another factor has to be taken into account: in the sequel, we will consider the influence of structural changes in the fluid.

\section{Change of the size of DF and of the structure factor}

Section III A allowed us to compute the structure factor $S(0)$. Section III B 1 showed that $S(0)$ and $\xi$ increased with the addition of ions at 30 and $35 \mathrm{MPa}( \pm 0.5 \mathrm{MPa})$ and that the bigger the ionic radius (or the atomic number) of the cation, the larger the increase. Furthermore, the effect of $P$ is qualitatively the same for $\mathrm{XBr}$ aqueous solutions as for pure water: the maximum values of $\xi$ and $S(0)$ decrease with $P$ (Figures 6 and 7).

a. At the mesoscopic scale. If the spatial distribution of ions was homogeneous in the supercritical domain, their addition would not change the density contrast. However, we observed a change of the structure factor $S(0)$ : since $S(0)$ is proportional to the density contrast, this shows that the ions are distributed in a inhomogeneous way. In other words, the distribution of ions is different in the low density areas and in the high-density areas.

If the ions concentration increased in majority in the lowdensity areas, the ions would precipitate, because the density is too low for the ions to remain solvated. The observed mean density and scattered signal do not indicate any precipitation. The ions are thus located in majority in the high-density areas and they increase the structure factor. Note that it is consistent with the conclusions of Ref. 15 for $\mathrm{ZnBr}_{2}$ solutions.

b. Estimation of the number of ions in the DF. For a concentration of $0.33 \mathrm{~mol} / \mathrm{kg}$, there are 1 mole of $\mathrm{XBr}$ for on average 168 moles of water (i.e., 84 per cation), and for 1.0 $\mathrm{mol} / \mathrm{kg}$, there are 1 mole of $\mathrm{XBr}$ for on average 55 moles of water ( 28 per cation). Besides, if the typical size $\xi$ of the molecules clusters is about $20-25 \AA$, it corresponds at the critical pressure $(0.322 \mathrm{~g} / \mathrm{ml})$ to 18 moles of pure water and, as the density is higher in these clusters (for instance $0.7 \mathrm{~g} / \mathrm{ml}$ ) to 39 moles of water. Even with the higher concentration of the ions in these high-density areas, statistically there are just a few ions per cluster, depending on the concentration.

The difference of behavior according to the concentration of the ions can result from the proximity of these ions in the high density areas: at $0.33 \mathrm{~mol} / \mathrm{kg}$, only the interactions between the water molecules control the formation of the DF, whereas for higher concentration, the properties of the fluid may depend also on the interaction between the ions and the network of the water molecules and between the ions. In the case of $\mathrm{ZnBr}_{2}$ aqueous solutions, ${ }^{15}$ the temperature at the crossing of the critical isochore shifts for both concentrations of ions $(0.3 \mathrm{~mol} / \mathrm{kg}$ and $1.0 \mathrm{~mol} / \mathrm{kg})$, but in this case there are two bromide per cation $\mathrm{Zn}^{2+}$, which can explain this difference (even if this explanation is not valid to explain the difference of shifts between $\mathrm{XBr}$ and $\mathrm{NaCl}$ solutions). It thus seems that the ion concentration affects the formation of the $\mathrm{DF}$, starting from a threshold value, where a certain amount of ions is present in the DF.

c. At the intermolecular scale. In fact, the presence of the ions could even change the structure of the fluid itself and especially the local structure. According to Bouazizi et al. ${ }^{13}$ and based on neutron diffraction experiments, in $\mathrm{NaCl}$ aqueous solutions the intramolecular water structure is not affected by the presence of ions contrary to the intermolecular structure: an increase of $\mathrm{NaCl}$ concentration leads to a decrease of the number of hydrogen bond per molecule and to changes in the orientational ordering of a pair of hydrogenbonded molecules. Waluyo et al. ${ }^{14}$ show thanks to X-ray Raman scattering and SAXS experiments that indeed, $\mathrm{Na}^{+}$ weakens hydrogen bonds in water, whereas $\mathrm{Mg}^{2+}$ and $\mathrm{Al}^{3+}$ strengthen them and induce the formation of high-density hydration shells.

Depending on the characteristics of the ions, such as their charge, ionic radius, or atomic number, these effects could be more or less influential on the DF of the fluid. More precisely, we suggest two possible explanations, as follows:

1. Modification of the partition coefficient: this coefficient is defined as the ratio between the ions concentration in the liquid-like area and their concentration in the gaslike area. It is thus characteristic of the ions repartition in the fluid inhomogeneities. This coefficient could change depending on the solute in the solution and be different for different cations. Subsection III B 1 shows that bigger ions produce bigger structure factor; as the ions concentration is larger in the high-density areas, an increase in ionic radius could cause the increase of the partition coefficient.

2. Modification of the local structure of the fluid: the increase of the size of DF and of the structure factor could directly come from the size of these ions (without any change of the partition coefficient). Indeed, the variation of the size of the DF, that is the correlation length $\xi$, may increase with the size of the cations, in particular their ionic radius. Note that the maximum values of $\xi$ increase more than the ionic radius: the differences for $\xi_{\max }$ at 30 $\pm 0.5 \mathrm{MPa}$, are around $3.0 \pm 1.6 \AA$ between $\mathrm{Li}$ and $\mathrm{Rb}$ and around $4.6 \pm 1.6 \AA$ between $\mathrm{Li}$ and Cs. The ionic radius are worth, respectively, $0.74,1.5$, and $1.7 \AA$ for $\mathrm{Li}$, $\mathrm{Rb}$, and $\mathrm{Cs},{ }^{33}$ that is, differences of $0.76 \AA$ between $\mathrm{Li}$ and $\mathrm{Rb}$ and of $0.96 \AA$ between Li and Cs. The increase in ionic radius only does not explain the increase in $\xi$ : it is likely that the electrostatic effect has to be taken into account. Indeed the increase of $\xi$ could be a result of an increase of the number of water molecules in the clusters, these clusters developing around the solvation shells of the ions (including the bromine anion, whose solvation shell can have up to six oxygen neighbors ${ }^{35}$ ). This is the same conclusion as in Ref. 15. In the same vein, as the interaction between water and ions is 
typically electrostatic, the increase of the atomic number of the cations and their number of electrons may cause the observed increase of the structure factor $S(0)$.

In summary, the shift of the critical point, and especially the change of the critical pressure at $0.33 \mathrm{~mol} / \mathrm{kg}$ could explain the differences of the DF between pure water and aqueous solution. For a given $P$, the temperature at the crossing of the critical isochore is closer to the critical point when ions are added; this causes an increase of the size of the DF and of the structure factor. In addition to the shift of the critical isochore, the structural parameters of the cations may explain the increase of the DF with their electronic density and atomic number.

\section{CONCLUSION}

The presence of $\mathrm{XBr}$ salts $(\mathrm{X}=\mathrm{Li}, \mathrm{Rb}$, or $\mathrm{Cs})$ in aqueous solutions changes the density fluctuations of water: at low concentration $(0.33 \mathrm{~mol} / \mathrm{kg})$ the size of the fluctuations and the structure factor increase, and these increases are positively correlated with the atomic number of the cation. As the temperature rises, their maximum is attained for the same value of $T$ as for pure water, regardless of the choice of X. For higher concentration $(1.0 \mathrm{~mol} / \mathrm{kg})$, on the contrary, this maximum is attained at higher $T$. Furthermore, the critical pressure of the system increases with respect to pure water case in presence of ions.

These behaviors are caused by two simultaneous effects: one is a change of the critical point and the second one is the differences of electronic densities between the ions. Indeed, the change of coordinates of the critical point with the addition of ions may explain a part of the increase of the size of the fluctuations and of the structure factor. This effect may account for the differences between pure water and aqueous solutions; however, it does not account for the differences between distinct $\mathrm{XBr}$ solutions with various $\mathrm{X}$. Besides, as the ions are located in majority in the high density areas, the differences of the size of the density fluctuations among the ions could be explained by differences of electronic densities between these ions, through electrostatic interactions.

It is currently difficult to distinguish between these two effects (shift of the critical point and differences between the aqueous solutions) due to an insufficient knowledge of the critical point of $\mathrm{XBr}$ solutions as a function of the concentration. If such data were available, in the spirit of the work of Bischoff and Pitzer ${ }^{19}$ for $\mathrm{NaCl}$, it would lead to a far better understanding of the phenomena in the supercritical domain, and especially the density fluctuations. The differences between XBr solutions may be caused by structural modifications, such as changes of the local structure between the water molecules and especially the number of hydrogen bond, that depend on the size and atomic number of the cations.
${ }^{1}$ A. Kalinichev, Rev. Mineral. Geochem. 42, 83 (2001).

${ }^{2}$ S. Tucker, Chem. Rev. 99, 391 (1999).

${ }^{3} \mathrm{H}$. Stanley, Introduction to Phase Transitions and Critical Phenomena (Clarendon, Oxford, 1971).

${ }^{4}$ K. Nishikawa and T. Morita, Chem. Phys. Lett. 316, 238 (2000).

${ }^{5}$ K. Nishikawa and I. Tanaka, Chem. Phys. Lett. 244, 149 (1995).

${ }^{6}$ Y. Tanaka, Y. Takahashi, T. Morita, and K. Nishikawa, Jpn. J. Appl. Phys. 47, 334 (2008).

${ }^{7}$ D. Sullivan, G. Neilson, H. Fischer, and A. Rennie, J. Phys.: Condens. Matter 12, 3531 (2000).

${ }^{8}$ M. Bonetti, G. Romet-Lemonne, P. Calmettes, and M.-C. Bellissent-Funel, J. Chem. Phys. 112, 268 (2000).

${ }^{9}$ T. Morita, K. Kusano, H. Ochiai, K.-I. Saitow, and K. Nishikawa, J. Chem. Phys. 112, 4203 (2000).

${ }^{10}$ T. Morita, Y. Takahashi, Y. Tanaka, A. Arai, and K. Nishikawa, J. Chem. Phys. 124, 124519 (2006).

${ }^{11}$ T. Morita, K. Kusano, K. Nishikawa, H. Miyagi, Y. Shimokawa, and H. Matsuo, Rev. Sci. Instrum. 72, 3013 (2001).

${ }^{12}$ B. Kamgar-Parsi, J. L. Sengers, and J. Sengers, J. Phys. Chem. Ref. Data 12, 513 (1983)

${ }^{13}$ S. Bouazizi, F. Hammami, S. Nasr, and M.-C. Bellissent-Funel, J. Mol. Struct. 892, 47 (2008).

${ }^{14}$ I. Waluyo, C. Huang, D. Nordlund, U. Bergmann, T. Weiss, L. Pettersson, and A. Nilsson, J. Chem. Phys. 134, 064513 (2011).

${ }^{15}$ D. Testemale, M.-V. Coulet, J.-L. Hazemann, J.-P. Simon, F. Bley, O. Geaymond, and R. Argoud, J. Chem. Phys. 122, 194505 (2005).

${ }^{16}$ V. Simonet, Y. Calzavara, J. Hazemann, R. Argoud, O. Geaymond, and D. Raoux, J. Chem. Phys. 116, 2997 (2002).

${ }^{17}$ V. Simonet, Y. Calzavara, J. Hazemann, R. Argoud, O. Geaymond, and D. Raoux, J. Chem. Phys. 117, 2771 (2002).

${ }^{18} \mathrm{C}$. Da Silva-Cadoux, Thèse de doctorat, Université Joseph Fourier, Grenoble, 2008.

${ }^{19}$ J. Bischoff and K. Pitzer, Am. J. Sci. 289, 217 (1989).

${ }^{20}$ J. P. Simon, S. Arnaud, F. Bley, J. F. Berar, B. Caillot, V. Comparat, E. Geissler, A. de Geyer, P. Jeantey, F. Livet, and H. Okuda, J. Appl. Crystallogr. 30, 900 (1997).

${ }^{21}$ D. Testemale, R. Argoud, O. Geaymond, and J.-L. Hazemann, Rev. Sci. Instrum. 76, 043905 (2005).

${ }^{22}$ R. Bruyère, A. Prat, C. Goujon, and J.-L. Hazemann, J. Phys.: Conf. Ser. 121, 122003 (2008).

${ }^{23}$ D. Boryta, J. Chem. Eng. Data 15, 142 (1970).

${ }^{24}$ I. Harsányi, L. Pusztai, J.-C. Soetens, and P. Bopp, J. Mol. Liq. 129, 80 (2006).

${ }^{25}$ S. Ballard, L. Combes, and K. McCarthy, J. Opt. Soc. Am. 42, 65 (1952).

${ }^{26}$ P. Damay, F. Leclercq, and P. Chieux, Phys. Rev. B 40, 4696 (1989).

${ }^{27}$ P. Damay, F. Leclercq, R. Magli, F. Formisano, and P. Lindner, Phys. Rev. B 58, 12038 (1998).

${ }^{28}$ M.-V. Coulet, V. Simonet, Y. Calzavara, D. Testemale, J.-L. Hazemann, D. Raoux, F. Bley, and J.-P. Simon, J. Chem. Phys. 118, 11235 (2003).

${ }^{29}$ A. Levelut and A. Guinier, Bull. Soc. Fr. Mineral. Cristallogr. 90, 445 (1967).

${ }^{30}$ E. Lemmon, M. McLinden, and D. Friend, "Thermophysical properties of fluid systems," in WebBook de chimie NIST, Base de Données Standard de référence NIST numéro 69 edited by P. J. Linstrom and W. G. Mallard (National Institute of Standards and Technology, Gaithersburg MD, 2005) See http://webbook.nist.gov.

${ }^{31}$ A. K. Wyczalkowska, K. S. Abdulkadirova, M. A. Anisimov, and J. V. Sengers, J. Chem. Phys. 113, 4985 (2000).

${ }^{32} \mathrm{M}$. A. Veloso, in International Nuclear Atlantic Conference (INAC) Innovations in Nuclear Technology for a Sustainable Future; ENFIR Meeting on Nuclear Reactor Physics and Thermal Hydraulics, Rio de Janeiro, RJ, Brazil (2009).

${ }^{33}$ M. Yizhak, Chem. Rev. 88, 1475 (1988).

${ }^{34}$ C. Da Silva, O. Proux, J. Hazemann, J. James-Smith, D. Testemale, and T. Yamaguchi, J. Mol. Liq. 147, 83 (2009).

${ }^{35}$ P. Merkling, R. Ayala, J. MartÃnez, R. Pappalardo, and E. Marcos, J. Chem. Phys. 119, 6647 (2003). 